\title{
The Techniques to Control a Space Laboratory Orbital Motion During Conducting of Gravity-sensitive Processes on Its Board
}

\author{
A. V. Sedelnikov \\ Departament of Space Mechanical Engineering of Samara State Aerospace University, Samara, Russia
}

Email address:

axe_backdraft@inbox.ru

To cite this article:

A. V. Sedelnikov. The Techniques to Control a Space Laboratory Orbital Motion During Conducting of Gravity-Sensitive Processes on Its Board. American Journal of Aerospace Engineering. Special Issue: Space Laboratories: History, Researches, Prospects.

Vol. 3, No. 1-1, 2015, pp. 6-9. doi: 10.11648/j.ajae.s.2016030101.12

\begin{abstract}
The following article deals with three different techniques to control orbital motion of spacecraft with big flexible structures during conducting of gravity-sensitive processes on its board. These processes require low level of microaccelerations. There were given examples of application of the techniques, recommendations for application of these techniques in practice, discussed advantages and disadvantages of each technique.
\end{abstract}

Keywords: Control of Orbital Motion, Level of Microaccelerations, Gravity-Sensitive Processes

\section{Introduction}

Conducting of gravity-sensitive processes on a board of spacecraft requires low level of microaccelerations [1]. The technological processes which require level of microaccelerations about $10^{-7} \mathrm{~g}$ are worked out. It is very difficult to support such level. Most of these processes are energy-intensive. It is necessary to use big solar paddles for its conducting. The constant orientation of spacecraft on its orbit is necessary for effective use of solar paddles. Running of attitude engines has a negative effect on facilities for technological processes [2]. The firing of engines causes a sudden increase of microacceleration level. It leads to unsuccessful carrying out of the processes. That is why the problem of optimal control of spacecraft on its orbit is of great urgency.

\section{Total Experience, Taking into Account the Last Projects}

\subsection{Unoriented Orbital Flights}

The practice in conducting of unoriented orbital flights of technological spacecraft from line of "Foton" ("Foton-1", "Foton-M" No 3 (figure 1)) showed two significant disadvantages of this approach.
1. Short operational term of spacecraft on its orbit.

In case of the longest flight operational term was less than 18 days [1]. The term is not enough for conducting of long gravity-sensitive processes on a board of spacecraft.

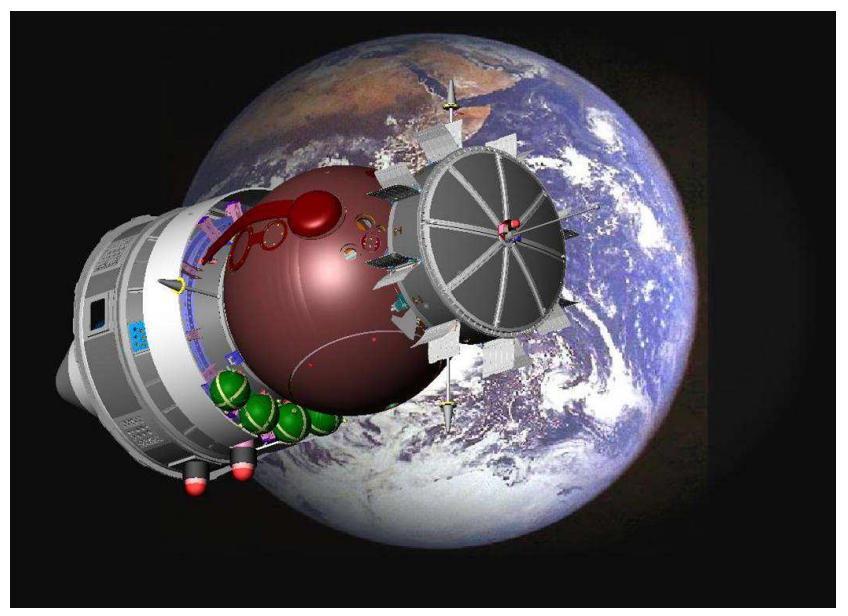

Figure 1. Space laboratoty “Foton-M" No 3.

2. Unoriented flight leads to promotion of spacecraft.

A rotational speed of "Foton-M" No 2 (figure 1) rose in 10 times in the end of the operational term, speed of «Foton-M» No 3 rose in 3 times [3]. This fact significantly involves an estimation of microacceleration level and prediction of probability of successful carrying out of technological 
processes [4].

These disadvantages are inappropriate for the most of gravity-sensitive processes. To eliminate defects it is necessary to control spacecraft orbital motion.

For maintenance of required orientation it is necessary to use different facilities such as gyroscopes and gyrodines. These facilities accumulate an angular momentum from factors which disturb a motion of spacecraft. The main problem of this orientation scheme is to search the methods to reduce this momentum.

\subsection{The Technique 1. the Application of Low Thrust Liquid Rocket Engines}

These engines run in pulse mode. When an angular velocity of wheel of gyroscope or gyrodine becomes critical, the engine starts. It causes a reactive moment around center of mass of spacecraft (about 4-10 N.m) and stimulate reduction of angular momentum of wheel of gyroscope or gyrodine. The technique was used on "Skylab" (figure 2), "Bion-M" No 1 (figure 3) and other spacecraft.

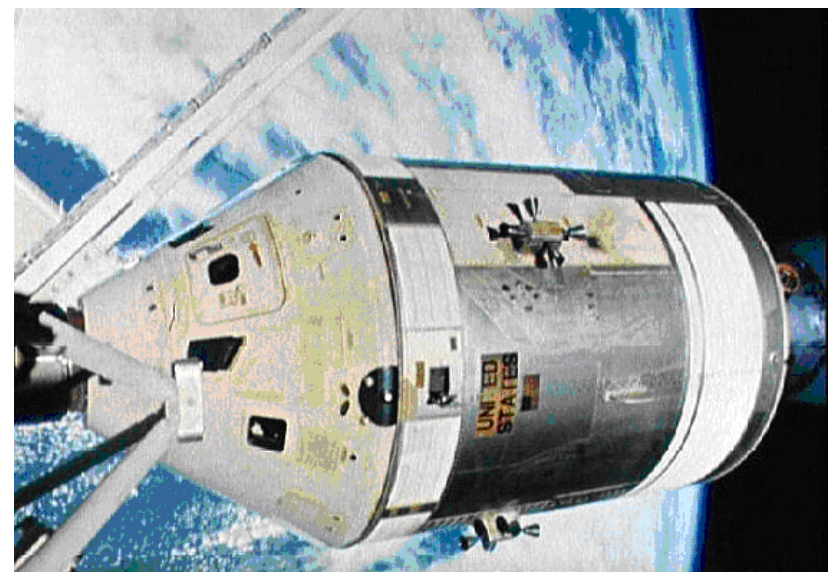

Figure 2. Space laboratoty "Skylab".

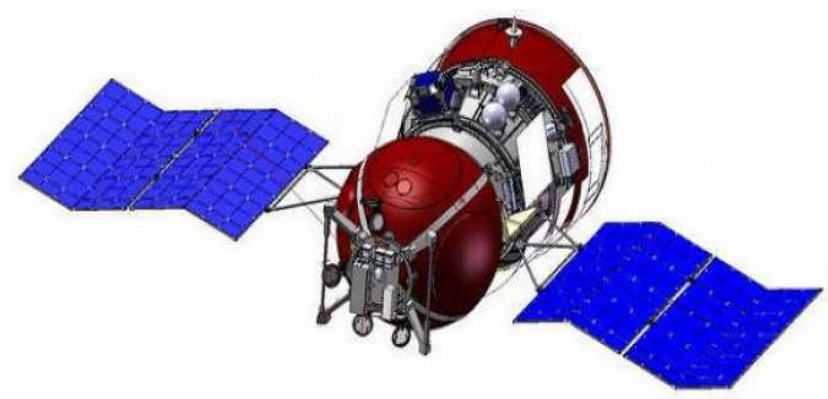

Figure 3. Space laboratoty “Bion-M” No 1.

The advantages of this technique are listed below:

- effectiveness of orbital motion control;

- small fuel consumption for orientation control.

However, there are some disadvantages:

- engine firing can cause an increase of microaccelerations to $10^{-3} \mathrm{~g}$;

- engine firing causes oscillations of big flexible structures.

\subsection{The Technique 2. the Application of Low Thrust Liquid Rocket Engines and Electric Jet Engines}

This perspective technique to control orbital motion for successful conducting of gravity-sensitive processes is described in article [5]. The advantages of this technique are listed below:

- a constant running of electrojet engine (figure 4) allows to raise a time interval between firings of liquid rocket engines;

- it is possible to use solar wind as a fuel in the long term.

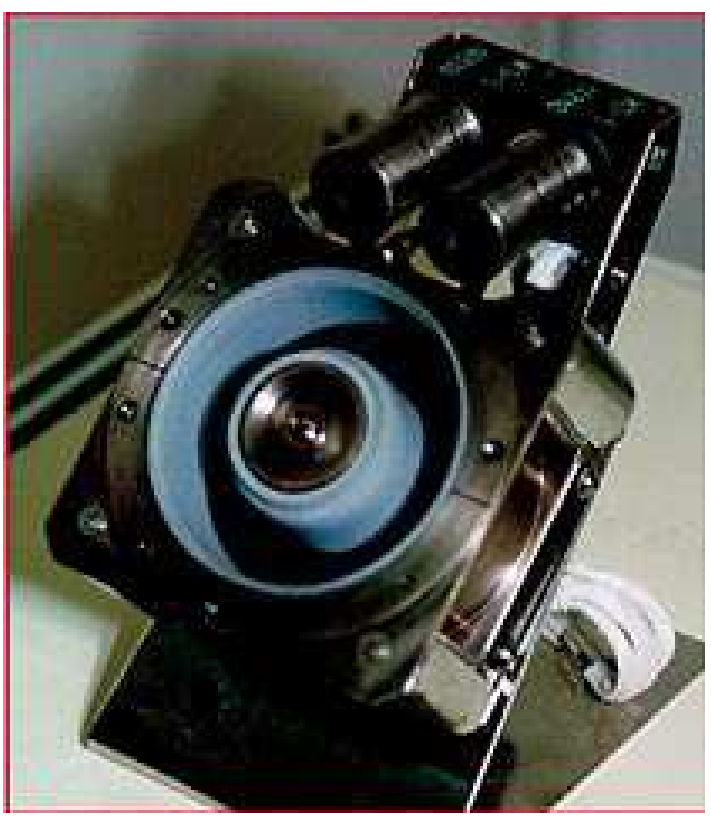

Figure 4. Electrojet engine SPD-100 [6].

Table 1. Main Characteristics of SPD-100

\begin{tabular}{ll}
\hline Caracteristic, dimension & Value \\
\hline Draft, $m N$ & 83 \\
Power consumption, $k W$ & 1,2 \\
Work resource, $h$ & 7500 \\
Mass, $k g$ & 3,5 \\
Specific impulse, $s$ & 1100 \\
Coefficient of efficiency & 0,3 \\
Level of microaccelerations, $\mu \mathrm{m} / \mathrm{s}^{2}$ & $0,01-0,03$ \\
\hline
\end{tabular}

\subsection{The Technique 3. the Application of Low Thrust Liquid} Rocket Engines and Flywheel Engines

Recently completed space project "Foton-M" No 4 was oriented by this new method. The low thrust liquid rocket engines stared only two times during the flight: after an orbital injection of spacecraft and before a launching of reentry vehicle. The spacecraft was oriented on the orbit by the system of attitude-control flywheel engines (figure 5) during all operational term. Indeed an advantage of this technique is that there is not any recent increase of microacceleration level which is usually caused by firings of attitude engines. However techniques 1 and 2 have a 
common disadvantage. During impulse firings a level of microaccelerations can decrease to $10^{-7} \mathrm{~g}$. A constant running of electric jet engine or system of flywheel engines can lead to minimal microacceleration level about $(1 \ldots 3) \cdot 10^{-6} \mathrm{~g}$. Unfortunately, there were some problems during realization of "Foton-M" No 4. That is why we can't consider this project to be absolutely successful. "Foton-M" No 4 wasn't launched to the operational orbit because of loss of communication with spacecraft in the beginning of the flight. According to preliminary estimates microacceleration level at perigee could rise to $10^{-4} \mathrm{~g}$ instead of $10^{-5}-10^{-6} \mathrm{~g}$ because of great aerodynamic disturbance. As the result duration of the experiments was shorten. The operational term of the spacecraft was diminished from 60 to 42 days.

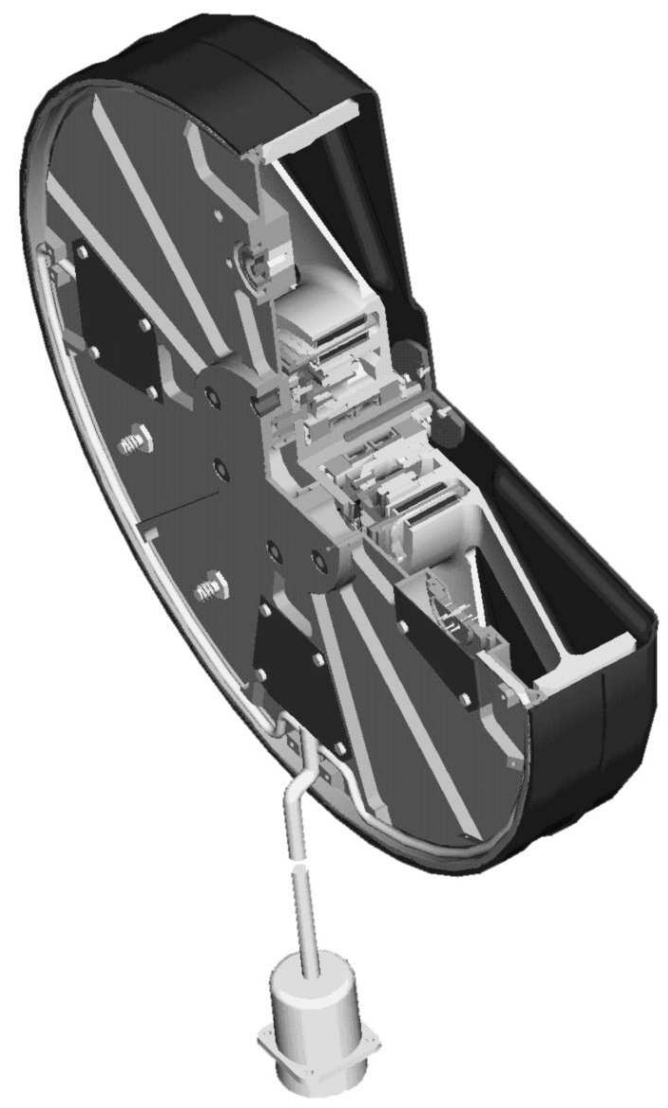

Figure 5. Flywheel engines [7].

\subsection{Space Laboratory “Foton-M” No 4}

In spite of the difficulties "Foton-M" No 4 (figure 6) nowadays is the most progressive realized project. The realization of this project allowed conducting of the longest biological experiments on the board of autonomous unmanned space laboratory. New control system of orbital motion allows maintaining low microacceleration level about $10^{-6} \mathrm{~g}$ during all operational term of space laboratory (to 60 days). Test of this control system will allow using of it also in more significant space projects [8,9]. For example, the project of reusable space laboratory "OKA-T" (figure 7) is being developed in Russia at the present time [1]. Laboratory will be tended by international space station. It will allow raising its operational term to 5 years. At the same time "OKA-T" could be in an autonomous controlled flight to 90-100 days. Achievable level of microaccelerations on space laboratory "OKA-T" will be about $10^{-7} \mathrm{~g}$.

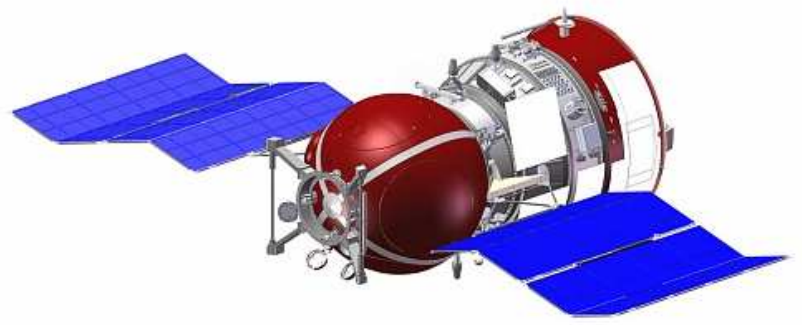

Figure 6. Space laboratoty "Foton-M" No 4 [10].

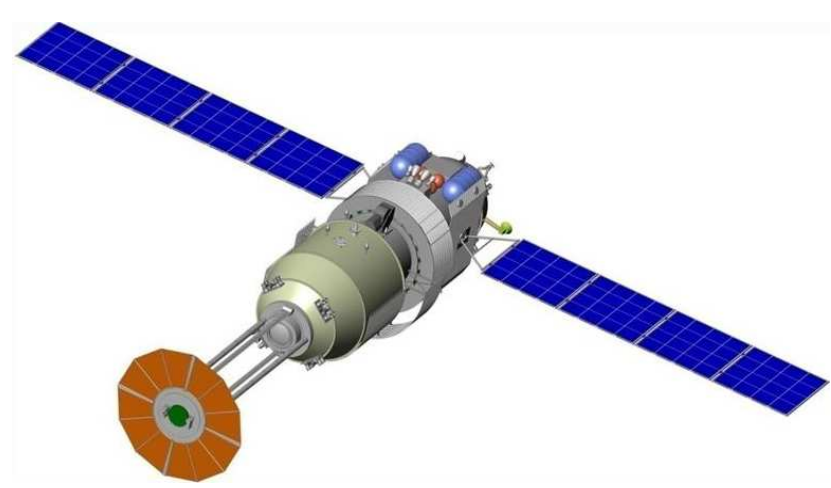

Figure 7. Space laboratoty “OKA-T” [11].

If the space laboratory is tended by international space station, time of return of experimental results to the Earth will rise. But some of the results should be delivered to the Earth quickly. That is why a project of small spacecraft "Vozvrat-MKA" is being developed now for quick launching of the experimental results.

\section{References}

[1] A.V. Sedelnikov The Problem of Microaccelerations: from Comprehension up to Fractal Model, (Moscow, Russian Academy of Sciences: The Elected Works of the Russian School, 2012), p. 277.

[2] A.I. Belousov and A.V. Sedelnikov "Problems in Formation and Control of a Required Microacceleration Level at Spacecraft Design, Tests, and Operation," Russian Aeronautics, vol. 57, No 2, 2014, pp.111-117.

[3] T. Beuselinck, Van C. Bavinchove, V.I. Abrashkin, A.E. Kazakova and V.V. Sazonov "Determination of the Spacecraft Foton M-3 Attitude Motion on Measurements of the Earth Magnetic Field," Preprint, Keldysh Institute of Applied Mathematics, Russia Academy of Sciences, No 80, 2008.

[4] A.I. Belousov and A.V. Sedelnikov "Probabilistic Estimation of Fulfilling Favorable Conditions to Realize the Gravity-sensitive Processes Aboard a Space Laboratory," Russian Aeronautics, vol. 56, No 3, 2013, pp.297-302. 
[5] A.V. Sedelnikov and A.A. Kireeva "Alternative solutions to increase the duration of microgravity calm period on board the space laboratory," Acta Astronautica, vol. 69, 2011, pp. $480-484$.

[6] A.V. Sedelnikov, E.Yu. Sygurova and A.A. Kireeva "The Use of Electric Engine to Reduce the Microaccelerations Level of Space lab," Messenger the Samara State Aerospace University name of the academician of S. P. Korolev (national research university), No 3 (34), part 2, 2012, pp. 16-20.

[7] A.G. Brovkin, B.G. Burdygov and S.V. Gordiyko Anboard control systems of spacecrafts, (Moskow, Publishing house of MAI-PRINT, 2010), p. 304.
[8] A.V. Sedelnikov "Fractal quality of microaccelerations," Microgravity Scienes and Technology, vol. 24, No 5, 2012, pp.345-350.

[9] A.V. Sedelnikov "The usage of fractal quality for microacceleration data recovery and for measuring equipment efficiency check," Microgravity Scienes and Technology, vol. 26, No 5, 2014, pp.327-334.

[10] V.I. Abrashkin "Preparation of the TUS space experiment for UHECR study," International Journal of Modern Physics A, vol. 20, No 29, 2005, pp. 6865-6868.

[11] Patent RU 2181094 C1 29.08.2000. 